\title{
Higher Education's Contributions to the U.S. Democratic Society
}

\author{
Robert L. Williams, PhD \\ University of Tennessee, Knoxville, Tennessee, United States \\ Charaya C. Upton, MA \\ University of Tennessee, Knoxville, Tennessee, United States
}

Contact: bobwilliams@utk.edu

\section{Abstract}

College experiences can contribute to teaching, learning, and instruction within higher education. The framework for this essay treats the college community as prototypic of the U.S. political society. Several aspects of the national political culture have been approximated within a collegiate culture. For example, every political problem within our society can be represented in a miniature fashion within a program of studies in a university. Much of students' political information can come from the interaction between teachers and students. However, a sizable portion of this learned information can extend through interaction among students. At that point, teachers would point students to information that expands their reservoir of collegiate information. Ultimately, students would refine their political information by exchanging valuable information with one another, as well as with their teachers. We have chosen to target higher education rather than pre-collegiate levels in emphasizing how higher education and our democratic system of government can be intertwined. We highlight the possibilities of college students' understanding and appreciating others' political views in working with one another rather than against one another in educational and political planning. Specifically, we include in this report the following issues: (a) political information resources routinely available in higher education, (b) college students' learning to participate in broader political conversation, (c) college students' examination of high profile U.S. constitutional declarations, (d) college students' deepened comprehension of their own political perspectives, and (e) college students' understanding that the knowledge derived from higher education can strengthen our democratic system of government.

Keywords: higher education, active listening, democracy, bipartisanship

Date Submitted: April 6, 2021 | Date Published: September 22, 2021

\section{Recommended Citation}

Williams, R. L., \& Upton, C. C. (2021). Higher education's contributions to the U.S. democratic society. Journal of Educational Research and Practice, 11, 220-231. https://doi.org/10.5590/JERAP.2021.11.1.16

\section{Introduction}

Political parties from 2010 to 2020 came to view college education differently. In 2010, $58 \%$ of Republicans viewed a college education as having a positive impact on U.S. Culture. However, in the period from 2015 to 2020, when President Trump dominated U.S. politics, approval of a college education by Republicans 
dropped to 33\% (Pinsker, 2019). Our research review primarily targets how higher education can strengthen our democratic government, including solutions to both routine societal challenges and challenges of historical significance, such as the selection of presidents.

Higher education is an integral part of the U.S. democratic system and the knowledge created within higher education can fundamentally affect democracy. Thus, the most critical questions about higher education are not about how it will affect our political parties, but rather how it can affect our overall democratic system of government. At this point, the emphasis in our society appears to be more on how higher education can strengthen specific parties rather than impact our overall democratic system, which may not emerge from one or more strong parties.

\section{Higher Education Students' Political Information Sources}

Faculty members who teach college courses have been likely to classify themselves as Moderates (46.1\%) or Liberals (44.1\%), with only 9.2\% regarding themselves as Conservatives (Jaschik, 2017). On one liberal college faculty, $61 \%$ of faculty members had identified themselves as Liberals, and only $3.9 \%$ as Conservatives. Another recent report by Jaschik (2018) of college freshmen revealed that liberalism and conservatism may be progressing toward more equivalent status in higher education among students. A survey of more than 7,000 first-year students in more than 120 4-year colleges revealed that close to $50 \%$ of the initially liberal and conservative students became more favorable toward the opposing political orientations from the beginning to the end of their freshmen year.

On the other hand, approximately 20\% of the students in the Jaschik report (2018) did not change their preference from their freshmen to sophomore year. Ultimately, about 30\% of the students became more negative toward the opposing orientation in their first collegiate year. Although Conservatives and Liberals are not consistently becoming more favorable or negative toward each other in higher education, their movement toward or away from each other in higher education appears to be becoming more similar.

Historical differences in political information sources for liberal and conservative students were reported by viewers of the Fox and CNN television networks more than a decade ago (Rosentiel, 2009). The difference between the percentage of Republican and Democratic viewers was greater on CNN than on FOX during that period and has become even more pronounced, according to a recent report from the Pew Research Center (Jurkowitz et al., 2020). This latter report indicated that the differences in sources from which conservative and liberal students get their political information became more pronounced rather than different during the first decade of the 20th century (see Table 1).

Table 1. Previous Percentages of Political Parties That Viewed Fox News and CNN in 2009

\begin{tabular}{lcc}
\hline News Network & Republicans & Democrats \\
\hline Fox News & $39 \%$ & $33 \%$ \\
CNN & $18 \%$ & $51 \%$ \\
\hline
\end{tabular}

Slightly less than $25 \%$ of Liberals and Conservatives cross over periodically to sample news from both Fox and CNN. The difference between Fox and CNN viewers is underscored most graphically by their ratings of President Trump's handling of COVID-19. Specifically, 63\% of the Fox viewers rated Trump's early handling of this disease as excellent, whereas only $7 \%$ of the $\mathrm{CNN}$ viewers rated his handling the virus as excellent (Gramlich, 2019).

Although students and faculty from different political backgrounds differ in their primary sources for political information, they also differed in their broadly-used information sources (e.g., NBC, ABC, CBS, and NPR) 
Williams \& Upton, 2021

with Liberals using these sources substantially more than Conservatives; NPR, in particular, was used several times more by Liberals than Conservatives (Grieco, 2020, April 1). Also, nationally read newspapers (e.g., New York Times, Washington Post) are accessed several times more frequently by Liberal than Conservative readers (Jurkowitz et al., 2020). Thus, not only do Conservative and Liberal students possibly differ in the political information to which they are exposed in college classes, the political information they bring to those classes is also substantially different for Conservative and Liberal students.

Possible dialogue between teachers and students of different political persuasions can be enhanced by informal question and answer exchanges following teachers' formal presentations of political information. Potential give and take in less formal discussions about political information could include such teacher and student questions as the following: (a) Do party differences or party similarities contribute more to a democratic society? (b) What array of political values contribute the most to a democratic system? (c) How can society determine whether one party is contributing more to a democratic government than is another party? (d) Is it possible that one or more strong political parties can undermine a democratic system of government? Being able to discuss such questions with respectable demeanor could be one of higher education's greatest contributors to our democratic system of government.

\section{College Students' Participation in National Elections}

The primary way college students have been involved in national politics is through voting. All young adults (18+ years old) were authorized to vote in all U.S. states by the 26th amendment to the Constitution in July of 1971. According to the National Center for Educational Statistics (n.d.), data from 2017 showed that out of the 2.9 million students who graduated from high school, approximately $67 \%$ of them ( 1.9 million) also enrolled in college. Recent evidence suggests that universities are producing a higher percentage of voting students than in previous years in the 20th century (Gross, 2018; Nietzel, 2019). In fact, universities doubled the 19\% voting rate of college students in the 2014 mid-term election to $40 \%$ in the 2018 mid-term election (Thomas et al., 2019).

In the months following the 2020 elections, extreme voting restrictions were advanced in most states by parties whose candidates were not elected in the 2020 national elections (Berman, 2021; Levine, 2021). Possibly no other issue is more important in a democratic society than the specification of voting rights. These proposed voting changes mainly highlight the difficulty versus ease of voting. That dimension primarily specified limited times and locations for voting. In some cases, restricting voting times and locations have appeared to target selected minority groups. Students in higher education will need to consider whether making voting easier or more difficult for everyone will actually favor some groups over other groups. For example, poorer voters are likely to be especially disadvantaged by reducing the times and increasing the distances of voting locations (Sweren-Becker, 2021).

Possibly the most salient issues for discussion following the more formal presentation regarding student voting would be the possibility and impact of making voting more difficult or easy. Questions could target any or all of the following issues. (a) How would increasing the difficulty of voting affect the integrity of voting? (b) How could the increased difficulty of voting be deflected by college students? (c) Why would approximately $50 \%$ of college-age adults not participate in national elections? (d) What could teachers and voting students do to elevate this percentage in the college voters to well above 50\%? (e) Overall, is the well-being of the U.S. democracy better served by making voting easier or more difficult for prospective voters?

\section{College Students' Assessment of Selected U.S. Constitutional Issues}

Given the possibility that some of the most debatable practices in our Democracy are anchored in the U.S. Constitution, college students need to be well informed about the linkage between current political practices and selected passages in the Constitution. It is not too unusual to hear politicians refer to current political 
disputes as possibly leading to a constitutional crisis. Obviously, these issues can be hotly debated. Consequently, both faculty and students in higher education need to be well informed regarding what constitutional directives may still be debatable in contemporary political circles. One of the most efficient and readable texts on the Constitution is Raphael's book, The U.S. Constitution (2017). This book can give substantial background on the Constitution for some of our most contentious political issues.

We believe that three of the most debatable and significant issues anchored in the Constitution relate to the election of presidents, the longevity of appointment to the Supreme Court, and the types of guns that can be purchased for public use. Although all three of these issues can profoundly affect the quality of our society, how we select presidents can have a profound and enduring effect on our country's political integrity. Although individual votes are often considered the most democratic way to select political leaders, two of the last four presidents did not win the national vote. Instead, they were selected by an electoral college in which individuals represented millions of voters in many winner-take-all states.

Another issue about which both politicians and private citizens can be affected for extended periods is the selection of judges for the Supreme Court, which are usually assumed to be lifetime appointments. However, the Constitution does not guarantee lifetime appointments for selected judges, but rather allows them to serve as long as they wish as long as they can do so responsibly (Raphael, 2017). For most judges, that means a time period spanning several decades, possibly the remainder of judges' lives. Consequently, highly biased appointments to the Supreme Court can have adverse lifetime effects even on the youngest voters. Theoretically, judges are presumably appointed to the Supreme Court because of their political neutrality in interpreting the cases brought before the court. With respect to long-term service on the Supreme Court, acting justices have suggested term limits in the range of 15 to 18 years (Buchanan, 2020).

A third highly contentious constitutional issue relates to the type of firearms one can own and use in public areas and for what purposes. According to the Second Amendment, guns were to be used by a well-regulated militia to protect free states from the federal government's domination. However, the United State's relatively recent firearms death rates have been the highest by far of any democratic nation in the world (Gunpolicy.org; Masters \& Ro, 2013). Internationally, strict gun laws are usually paralleled by low gun death rates. Even in the U.S., where guns are readily available in most states, the states with stringent gun laws generally have the lowest gun homicides (Schoen, 2018).

The National Rifle Association has been strongly committed to protecting gun owners' rights by insisting on preserving broad interpretation of the Second Amendment. An important gun-control issue to discuss with students is whether this amendment is to be interpreted in the context of the times when the amendment was adopted or in the context of current times. Individuals who oppose some interpretations of the Second Amendment (e.g., any types of guns can be owned) may not insist on the abolishment of the Second Amendment, but rather the restriction of gun use that can kill large groups in a matter of seconds (Waldman, 2014).

Questions that might be appropriate in informal class discussion about constitutional change could include any or all of the following possibilities: (a) What would be the fairest way to select U.S. Presidents? (b) How could college students help most in attempting to change facets of these three constitutional issues? (c) Does our society generally benefit more from working on long-term constitutional changes or targeting short-term societal issues? (d) How has the Constitution adversely affected the passage of gun control? (e) Given the perceived urgency of changing some features of the Constitution, why has changing those features been so difficult? 


\section{College Students' Comprehension of Alternative Political Views}

One of the most significant impediments to effective political discussions between college instructors and students could be the extent to which students misinterpret or misrepresent others' political views. Common tendencies include "missing the point" of another's comment, overstating another's comment, moving the conversation to another issue before closure of a current issue, initially pointing out weaknesses rather than strengths in others' views, shaking one's head while others are speaking, supporting one's own views primarily with ideological claims rather than with empirical data, and fearing that tempering one's own views could be perceived by opposing politicians as procedural weakness. Obviously, there are many ways an authoritative conversation can go off track.

The most effective type of responding to complex educational and/or political conversations is identified in the literature as active listening. A succinct goal of active listening has been offered by McNaughton et al. (2007): "The goal in active listening is to develop a clear understanding of the speaker's concerns and also clearly communicate the listener's interest in those issues" (p. 224). In other words, it is important that listeners not proceed with their own views before conveying an understanding of the speaker's perspective (Hoppe, 2007).

Most assuredly, listeners should not state agreement or disagreement with a speaker's comment before an accurate understanding of that view has been acknowledged. Within this framework, Weger et al. (2014) indicated that active listening consists of three phases: (a) showing nonverbal attention to what the speaker is saying; (b) accurately paraphrasing the speaker's message; and (c) asking for further elaboration of the speaker's comments. Actually, active listening is probably the most comfortable form of listening for both speaker and listener.

Unfortunately, political discourse may be a domain where active listening is minimally displayed. Politicians often appear quick to interrupt and discredit others' views. In contrast, active listening is highly practiced in some of the most important professions in U.S. society (Weger et al., 2014), including education (McNaughton et al., 2007); medicine (Bryant, 2009; Fassaert et al., 2007); social work (Rogers \& Welch, 2009); and crisis management (Royce, 2005). It may be too late for most veteran politicians to appreciate the importance of active listening in their professional conversations. Still, any attempt to train college students to be politically astute in conversation must heavily emphasize active listening (see Table 2).

Table 2. Examples of Active Listening

\begin{tabular}{lc}
\hline Clarifying statements & Clarifying questions \\
\hline "You're saying that ...." & "Are you saying that ...?" \\
"Your point is that ...." & "Is your point that ...?" \\
"You believe that ...." & "Is your belief that ...?" \\
"You want to know ...." & "Are you asking if ...?" \\
\hline
\end{tabular}

Given the track record for active listening in both informal and formal contexts, what questions could best address why active listening is not more widely practiced in both contexts? (a) Inasmuch as active listening should be among the most powerful tools of teaching, why don't all teachers practice this communication style in relating to both students and fellow teachers? (b) Why would some individuals not see active listening as a sign of interpersonal strength? (c) What percentage of professional people you have known generally practice active listening? (d) Do most professional individuals you know practice active listening widely? (e) Is active listening equally important in a personal and professional context? 
Williams \& Upton, 2021

\section{College Students' Re-examination of Their Own Views}

Controversy for controversy's sake is not necessarily a productive conversational arrangement. However, the right kind of controversy may be one of the best ways to broaden one's educational and/or political perspectives. We can better appreciate the merit of another's view by attempting to restate the affirmative features of that view. An approach designed to broadly and deeply appreciate others' political views has been labeled structured controversy and is one of the least onerous ways of re-examining different views on an issue (Hess, 2009).

The structured controversy model can best be used by small groups of college students having different political views to evaluate an issue, with the students first attempting to accurately represent differences in their views. This process would typically involve three application phases: (a) advocating a randomly assigned view (e.g., partisanship or bipartisanship), (b) representing a different perspective from the first view presented, and (c) constructing a blended combination of multiple views. Structured controversy provides an opportunity for students to articulate not only their current position on an issue but also present and possibly embrace aspects of opposing positions (D’Eon \& Proctor, 2001).

Avery et al. (1999) claimed that the structured controversy model could be used in examining the merits of virtually any debatable notion. The teacher begins by identifying two subgroups that can articulate different options for an identified problem. For example, the teacher might identify a partisanship model for one subgroup and a bipartisanship approach for another subgroup addressing a political problem. Some students in both subgroups will likely already favor a bipartisan approach, and others a partisan approach. A random draw will determine which subgroup goes first in presenting its view. For example, one subgroup may be randomly chosen to give its preferred view in the initial round but its less-preferred perspective in the second round, with each subgroup presenting both perspectives and listening to both perspectives across the two rounds.

After each subgroup has made a case for each position and listened to a case made for each position, the combined subgroups across rounds will attempt to reach a consensus preference across those views. In other words, determine if the partisan or the bipartisan approach works better, or possibly some combination of the two approaches might prove more effective. One might be ill-advised to assume that because each subgroup has heard and presented both sides of an issue, they could readily find common ground between the two perspectives. A fundamental assumption underlying this claim is that common ground can best be found if each subgroup has had the experience of advocating each position and listening to others advocate each view. On the other hand, if subgroup members are preoccupied with one approach over another, they may persist with that view even after presenting both views themselves.

There are three possible channels to group decisions: (a) subgroups may stay with their initially preferred positions on an issue; (b) the two subgroups may both support the same position (partisan or bipartisan); (c) the subgroups may blend information from the two positions by combining elements from each position. The third outcome is most aligned with bipartisan problem-solving. Philosophically, a partisan thinker may be preoccupied with "what's in it for me?" On the other hand, the bipartisan thinker may attempt to find or create a solution that would incorporate features of both approaches (bipartisanship and partisanship) to capitalize on the benefits of both types of thinking. The healthiest form of a democracy may be a combination of partisanship and bipartisanship problem solving and planning.

Perhaps the most workable guideline for both of these perspectives would be "the greatest good for the greatest number in a subgroup" (Wareham et al., 2006, p. 656). When two subgroups have reached their conclusion, they can compare those conclusions and seek to unify them if they differ. Thus, any issue being addressed should include the following questions: How could some individuals benefit more from one solution than the other solution? How could the latter solution actually disadvantage some individuals? What 
solutions might actually benefit both subgroups? One or both subgroups and/or various members of one subgroup may have changed their views. Thus, exposure to both perspectives (bipartisanship and partisanship) may cause some individuals or subgroups to alter their initial preference and to reach an acceptable preference across individuals and/or subgroups (see Table 3).

Table 3. Alternative Outcomes

\begin{tabular}{ll}
\hline Conclusion reached & Outcome \\
\hline Keep the initial options intact & No common ground \\
Choose one of the other initial options & One intact stronger option \\
Blend the two initial options & Integrated features of both options \\
\hline
\end{tabular}

In the informal discussion following the formal presentation of multiple strategies to strengthen democratic government, the following questions may be helpful: (a)How would one integrate those strategies into a government program? (b) How is the blending of personal views one of the best ways to reach group conclusions? (c) How would you integrate the necessary steps in problem-solving to establish some sense of momentum? (d) Would you attempt to first identify the strongest notion for the intended legislation and extent it to kindred notions? (e) How do you convince others that working together leads to stronger outcomes than working competitively? (f) What have been the greatest cooperative achievements in your adult life?

\section{College Students' Involvement in Political Bipartisanship}

In an international meta-analysis comparing independent, competitive, and cooperative learning, cooperation proved to be the most effective across 164 studies in North America, Europe, Middle East, Asia, Africa, and the U.S. (Johnson et al., 2000). This cooperative superiority was determined in a variety of assessment procedures, including teacher-made tests, grades, standardized tests, presentations, and educational reports. In an extended meta-analysis involving 46 studies related to team problem-solving, teams having joint goals, mutual rewards, shared resources, and complementary roles outperformed teams working competitively on the different modes of problem-solving.

As attractive as bipartisanship may sound, it is not the principal mode of operation in American politics (Hamre, 2001). U.S. culture appears to have a very strong emphasis on competition in both work and play. Although 54\% of responders to a relatively recent Gallup Poll favored compromise among politicians, the strength of that preference differed by party affiliation: $44 \%$ of Republicans preferred compromise, while $62 \%$ of Democrats favored compromise (Newport, 2017). Conversely, in this same Gallup report, 23\% of the Republicans preferred that their political leaders stick to their ideological commitments. In contrast, only $12 \%$ of the Democratic responders preferred that their political leaders stand firm in their political allegiance (Newport, 2017).

Despite some attempts by congress to engage political opponents in a bipartisanship analysis, partisanship may still be preferred by voters. Paris's earlier article (2017) on "Breaking Down Bipartisanship; When and Why Citizens React to Cooperation across Party Lines" is one of the more revealing examinations of preferable ways to get things done in congress. Paris concluded that bipartisanship in politics (working across party lines) is supported by the public only when it results in legislative accomplishments (bills are passed). Attempts by Congress to function in a bipartisan fashion appear unlikely to be endorsed by the electorate.

Bipartisanship has occasionally been represented as a moderate approach that is safer than far-right or far-left positions (Fiorina et al., 2005). Trubowitz and Mellow (2005) previously asserted that some politicians periodically vote with the opposing party to project an image of moderation in addressing political problems. 
Occasionally, voting with the opposing party periodically counters an image of being controlled by specialinterest groups (Hibbing \& Theiss-Morse, 2005). Furthermore, political compromise can dispel some of the animosity that many party loyalists have toward opposing party members and even help the party loyalists to listen more favorably to opposing party members (Paris, 2017). Recent research shows that most Americans want political compromise but anticipate that gridlock may get even worsen in this pursuit (Bailey \& Elbeshbishi, 2021).

Lest we leave the impression that bipartisan rhetoric in congress would dispel much of the public negativity toward congress, we must underscore Morris and Witting's (2001) finding that congress's bipartisan rhetoric may intensify disapproval of congress's mode of operation. The distaste for typical congressional rhetoric is so deep and pervasive that any public exposure to congressional dialogue can precipitate distaste from the public. Our speculation is that much of this negativity has been spawned by how many congressional members have historically discredited others' views and sometimes even their integrity.

In a relatively recent publication, the late Senator Richard Lugar and former Representative Lee Hamilton expressed an international need for the U.S. to present a unified, bipartisan front (Lugar \& Hamilton, 2018). They recounted several instances in which prominent congressmen worked across party lines, even with an opposing president, to pass legislation dealing with such issues as the Anglo-Irish agreement and prohibition of torture against political prisoners. Also noteworthy, the Lugar Center publishes a Bipartisan Index that highlights examples of members of congress working across party lines to co-sponsor global arms control and food availability for the starving.

In Goodheart's (2010) contrast of the presidential styles of Barack Obama and Franklin Delano Roosevelt, Goodheart described Obama's style as "cool and self-possessed temperament" and Roosevelt's style as "engaging warmth and passion." However, Goodheart concluded his treatise with the observation that what the two presidential styles had in common was the "knowledge that politics in a democracy is the art of compromise" (p. 293). It may be that eventual compromise is more attainable in politics than members of opposing parties are inclined to admit. On the other hand, if participants (students in this case) can initially agree on something that each party can gain from in a mutual quest, they may become more comfortable in later discussing the possibilities of compromise.

In the informal discussion following the formal weighting of partisanship and bipartisanship in government, what would be some cogent questions regarding these notions in higher education and national politics? (a) What would be your personal preference for working in a bipartisanship versus nonpartisanship framework? (b) How often do you work in a partisan versus bipartisan context? (c) What has been your very best bipartisan work experience? (d) What has been your most problematic bipartisan work experience? (e) How will you avoid that problematic experience in the future?

\section{Higher Education's Possible Contributions to a Democratic Society}

To provide an example of how teachers could engage students in an informal examination of information included in teachers' formal presentations, we generated a series of questions that both teachers and students could introduce about the teacher's formal presentation of selected topics. Our suggested questions were initially introduced in the different sections of this report. We have left informal discussion of the selected questions up to teachers and students to examine.

These questions are potential issues that teachers and students could introduce to expand the scope and depth of formal information included in the various areas of this report. However, they are not intended to represent the full scope of questions that teachers and students might pose to expand and deepen discussion of issues covered in our report. Over time, teachers may expand their list of follow-up questions to see which topics are most conducive to further teacher-student discussion of this report. Starting questions are included in Table 4. 
Williams \& Upton, 2021

Table 4. Examples of Student-Teacher Discussion Questions

\begin{tabular}{|c|c|}
\hline Discussion topic & Potential questions \\
\hline $\begin{array}{l}\text { Political information sources in higher } \\
\text { education }\end{array}$ & $\begin{array}{l}\text { Do party differences or party similarities contribute } \\
\text { the most to a democratic society? } \\
\text { - What array of political values contribute the most to a } \\
\text { democratic society? }\end{array}$ \\
\hline $\begin{array}{l}\text { College students' participation in } \\
\text { politics }\end{array}$ & $\begin{array}{l}\text { - How would increasing the difficulty of voting affect the } \\
\text { integrity of voting? } \\
\text { - Why would approximately } 50 \% \text { of college-age adults } \\
\text { not participate in national elections? }\end{array}$ \\
\hline Possible changes in the Constitution & $\begin{array}{l}\text { - What would be the fairest way to select U.S. } \\
\text { Presidents? } \\
\text { - How has the Constitution adversely affected the } \\
\text { passage of gun control? }\end{array}$ \\
\hline $\begin{array}{l}\text { Pros and cons of alternative political } \\
\text { views }\end{array}$ & $\begin{array}{l}\text { - Why could active listening be among the most effective } \\
\text { teacher contributions to informal discussion with } \\
\text { students? } \\
\text { - Is active listening equally important in a personal } \\
\text { versus professional context? }\end{array}$ \\
\hline $\begin{array}{l}\text { College students' re-evaluation of their } \\
\text { views }\end{array}$ & $\begin{array}{l}\text { - How is blending personal views one of the best ways to } \\
\text { construct group outcomes? } \\
\text { - Why is working cooperatively better than working } \\
\text { competitively in reaching group conclusions? }\end{array}$ \\
\hline $\begin{array}{l}\text { College students' involvement in } \\
\text { political bipartisanship }\end{array}$ & $\begin{array}{l}\text { - What is the success rate of bipartisanship versus } \\
\text { partisanship in U.S. government planning? } \\
\text { - What are the most workable versus the most } \\
\text { problematic bipartisan practices? }\end{array}$ \\
\hline
\end{tabular}

Among our society's various political domains, higher education must assume an increasing role in promoting and protecting students' rights and responsibilities to vote. The logistics of free and fair elections, the multiplicity of voting opportunities, the protection of voters from intimidation, and most of all, extensive information on the major issues on which individuals vote. In other words, promoting all the reasons for students voting in democratic elections may constitute the greatest political challenge in higher education's becoming a prototype of democratic societies internationally. As Nelson Mandela once said, "Democracy and human rights are inseparable. We cannot have one without the other."

Among the questions that may prevail from examining a potential connection between higher education and a democratic U.S. society would be what constitutes the strongest link between the two domains. (a) The first question would be whether we can have one without the other. Can we have all the "bells and whistles" described for higher education without a society that functions democratically? (b) If not, what are the features that must prevail in higher education to nurture a democratic society? (c) On the other hand, what is indispensable in a democratic society to foster the pursuit of truth in all domains and at all levels of higher education? 


\section{References}

Avery, P. G., Johnson, D. W., Johnson, R. T., \& Mitchell, J. M. (1999). Teaching an understanding of war and peace through structured academic controversies. In A. Raviv, L. Oppenheimer \& D. Bar-Tal (Eds.), How children understand war and peace (pp. 260-280). Jossey-Bass.

Bailey, P. M., \& Elbeshbishi, S. (2021, April 27). Hidden Common Ground poll: Americans want compromise but think political gridlock will worsen. USA Today.

https://www.usatoday.com/story/news/politics/elections/hiddencommonground/2021/04/27/americ ans-want-compromise-but-think-divides-worsen-poll-finds/7201888002/

Berman, A. (2021, April 1). 361 voter suppression bills have already been introduced this year. Mother Jones. https://www.motherjones.com/politics/2021/04/361-voter-suppression-bills-have-already-beenintroduced-this-year

Bryant, I. (2009). The art of active listening. Practice Nurse 37(6), 49-52. https://www.fau.edu/CLASS/CRLA/Level_One/The_art_of_active_listening.pdf

Buchanan, M. J. (2020). The need for Supreme Court term limits. Center for American Progress. https://americanprogress.org/issues/reports/2029/o8/o3/488518/need-supreme-court-term-limits

D’Eon, M., \& Proctor, P. (2001). An innovative modification to structured controversy. Innovations in Education and Teaching International, 38(3), 251-256. https://doi.org/10.1080/14703290110051398

Fassaert, T., van Dulmen, S., Schellevis, F., \& Bensing, J. (2007). Active listening in medical consultations: Development of the Active Listening Observation Scale. Patient Education \& Counseling, 68(3), 258264. https://doi.org/10.1016/j.pec.2007.06.011

Fiorina, M. P., Abrams, S. J., \& Pope, J. (2005). Culture war? The myth of a polarized America. Longman.

Goodheart, E. (2010). Deconstructing left and right: The case for bipartisanship. Society 47(4), 286-294. https://doi.org/10.1007/s12115-010-9342-2

Gramlich, J. (2019, January 30). Partisans agree political leaders should be honest and ethical, disagree whether Trump fits the bill. Pew Research Center. https://www.pewresearch.org/facttank/2019/01/30/partisans-agree-political-leaders-should-be-honest-and-ethical-disagree-whethertrump-fits-the-bill/

Grieco, E. (2020, April 1). Americans' major sources for political news vary by party \& age. Pew Research Center. https://www.pewresearch.org/fact-tank/2020/04/o1/americans-main-sources-for-politicalnews-vary-by-party-and-age/

Gross, K. (2018, April 16). A new way to rank colleges: What percentage of students vote? New England Board of Higher Education. https://nebhe.org/journal/a-new-way-to-rank-colleges-what-percentageof-students-vote/

Gunpolicy.org. (n.d.). https://www.gunpolicy.org/

Hamre, J. J. (2001). Redefining bipartisanship. The Washington Quarterly. 24(2), 131-136.

Hess, A. (2020, August 24). 71\% of college students plan to vote in 2020-and they heavily prefer Biden over Trump. CNBC Make It. https://cnb.cx/3j2tFso

Hess, D. E. (2009). Controversy in the classroom. Routledge.

Hibbing, J. R., \& Theiss-Morse, E. (2005). Stealth democracy: Americans' beliefs about how government should work. Cambridge University Press.

Hoppe, M. H. (2007). Lending an ear: Why leaders must learn to listen actively. Leadership in Action, 27, 1114. 
Jaschik, S. (2017, February 27). Professors and politics: What the research says. Inside Higher Education. https://www.insidehighered.com/news/2017/02/27/research-confirms-professors-lean-leftquestions-assumptions-about-what-means

Jaschik, S. (2018, February 5). Liberal indoctrination? Not so much. Inside Higher Education. https://www.insidehighered.com/news/2018/02/05/research-suggests-colleges-broaden-studentspolitical-views

Johnson, D. W., Johnson, R. T., \& Stanne, M. B. (2000). Cooperative learning methods: A meta-analysis. University of Minnesota.

Jurkowitz, M., Mitchell, A., Sheaer, E., \& Walker, M. (2020, January 24). U.S. Media Polarization and the 2020 Election: A Nation Divided. Pew Research Center. https://www.journalism.org/wpcontent/uploads/sites/8/2020/01/PJ_2020.01.24_Media-Polarization_FINAL.pdf

Levine, S. (2021, January 28). Republicans considering more than 100 bills to restrict voting rights. The Guardian. https://www.theguardian.com/us-news/2021/jan/28/republicans-considering-100-billsrestrict-voting-rights

Lugar, R., \& Hamilton, D. (2018). A national security imperative: Bipartisan cooperation. The Hill. https://thehill.com/blogs/congress-blog/foreign-policy/410146-a-national-security-imperativebipartisan-cooperation

McNaughton, D. E., Hamlin, D., McCarthy, J., Head-Reeves, D., \& Schreiner, M. (2007). Learning to listen: Teaching an active listening strategy to preservice education professionals. Topics in Early Childhood in Special Education, 27(4), 223-231. https://doi.org/10.1177/0271121407311241

Morris, J., \& Witting, M. (2001). Congressional partisanship, bipartisanship and public opinion.: An experimental analysis. Politics and Policy, 20(1), 47-67. https://doi.org/10.1111/j.17471346.2001.tboo583.x

National Center for Educational Statistics. (2019, February). Immediate College Enrollment Rate. Retrieved on February 15, 2019, from https://nces.ed.gov/programs/coe/indicator_cpa.asp

Newport, F. (2017, October 9). Americans favor compromise to get things done in Washington. Gallup Poll. https://news.gallup.com/poll/220265/americans-favor-compromise-things-done-washinngton.aspx

Nietzel, M. T. (2019, September 24). College students voting doubled in 2018. What it could mean for 2020. Forbes. https://www.forbes.com/sites/michaeltnietzel/2019/09/24/college-students-take-to-thevoting-booth/?sh=6139d $3 \mathrm{~d} 253 \mathrm{eo}$

Paris, C. (2017). Breaking down bipartisanship. When and why citizens react to cooperation across party lines. Public Opinion Quarterly, 81(2), 473-494. https://doi.org/10.1093/poq/nfwo89

Pinsker, J. (2019, August 21). Republicans changed their mind about higher education really quickly. The Atlantic. https://www.theatlantic.com/education/archive/2019/08/republicans-conservativescollege/596497/

Raphael, R. (2017). The U.S. Constitution. Vintage Books.

Rogers, A., \& Welch, B. (2009). Using standardized clients in the classroom. An evaluation of a training module to teach active listening skills to social work students. Journal of Teaching in Social Work, 29(2), 153-168. https://doi.org/10.1080/08841230802238203

Rosentiel, T. (2009, October 30). Partisanship and cable news audiences. Pew Research Center. https://www.pewresearch.org/2009/10/30/partisanship-and-cable-news-audiences/

Royce, T. (2005). The negotiation and the bomber: Analyzing the critical role of active listening in crisis negotiation. Negotiation Journal, 21, 5-27. 
Schoen, J. W. (2018, February 27). States with strict gun laws have the fewest firearm deaths. Here's how your state stacks up. CNBC. https://www.cnbc.com/2018/02/27/states-with-strict-gun-laws-have-fewerfirearms-deaths-heres-how-your-state-stacks-up.html

Sweren-Becker, E. (2021, May 28). Florida Enacts Sweeping Voter Suppression Law. Brennan Center for Justice. https://www.brennancenter.org/our-work/analysis-opinion/florida-enacts-sweeping-votersuppression-law.

Thomas, N., Gismondi, A., Gautam, P., \& Brinker, D. (2019). Democracy counts. Increased student and institutional engagement. Institute for Democracy \& Higher Education at the Jonathan M. Tisch College of Civic Life, Tufts University. https://idhe.tufts.edu/sites/default/files/DemocracyCounts2018.pdf

Trubowitz, P., \& Mellow, N. (2005). Going bipartisan: Politics by other means. Political Science Quarterly, $120,433-453$.

Waldman, M. (2014). The second amendment doesn't say what you think it does. Mother Jones. https://motherjones.com/politics/2014/06/second-amendment-guns-michael-waldman

Wareham, D. G., Elefsiniotis, T. P., \& Elms, D. G. (2006). Introducing ethics using structured controversies. European Journal of Engineering Education, 31(6), 651-660. https://doi.org/10.1080/03043790600911712

Weger, H., Bell, G. C., Minei, E. M., \& Robinson, M. C. (2014). The relative effectiveness of active listening in initial interactions. International Journal of Listening, 28(1), 13-31. https://doi.org/10.1080/10904018.2013.813234

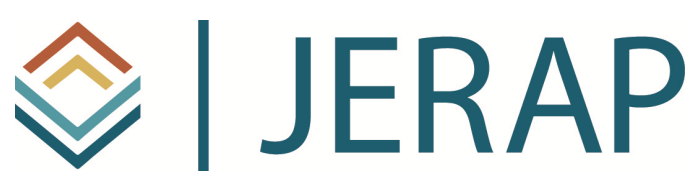

The Journal of Educational Research and Practice is a peerreviewed journal that provides a forum for studies and dialogue about developments and change in the field of education and learning. The journal includes research and related content that examine current relevant educational issues and processes. The aim is to provide readers with knowledge and with strategies to use that knowledge in educational or learning environments. JERAP focuses on education at all levels and in any setting, and includes peer-reviewed research reports, commentaries, book reviews, interviews of prominent individuals, and reports about educational practice. The journal is sponsored by The Richard W. Riley College of Education and Leadership at Walden University, and publication in JERAP is always free to authors and readers. 